\title{
Fuzzy sliding mode control of an offshore container crane
}

\author{
Quang Hieu Ngo ${ }^{1,3 *}$, Ngo Phong Nguyen ${ }^{2}$, Chi Ngon Nguyen ${ }^{2}$, Thanh Hung Tran ${ }^{2}$, Quang Phuc Ha ${ }^{3}$ \\ ${ }^{1}$ Department of Mechanical Engineering, Can Tho University, \\ 3/2 street, Ninh Kieu Dist., Can Tho City, Vietnam. \\ Tel: +84-710-3872133, Fax: +84-710-3831151, Email: nqhieu@ctu.edu.vn \\ ${ }^{2}$ College of Mechanical Engineering, Can Tho University of Technology, \\ 256 Nguyen Van $\mathrm{Cu}$ street, Ninh Kieu Dist., Can Tho City, Vietnam. \\ Tel: +82-42-350-1262, E-mail: nnphong@ @ctuet.edu.vn \\ ${ }^{3}$ School of Electrical, Mechanical and Mechatronic Systems, University of Technology Sydney, \\ PO Box 123 Broadway, NSW 2007, Australia. \\ Tel: +61 29514 2453, Fax: +61 29514 1810, Email: quang.ha@uts.edu.au
}

\begin{abstract}
A fuzzy sliding mode control strategy for offshore container cranes is investigated in this study. The offshore operations of loading and unloading containers are performed between a mega container ship, called the mother ship, and a smaller ship, called the mobile harbor $(\mathrm{MH})$, which is equipped with a container crane. The MH is used to transfer the containers, in the open sea, and deliver them to a conventional stevedoring port, thereby minimizing the port congestion and also eliminating the need of expanding outwards. The control objective during the loading and unloading process is to keep the payload in a desired tolerance in harsh conditions of the MH motion. The proposed control strategy combines a fuzzy sliding mode control law and a prediction algorithm based on Kalman filtering for the MH roll angle. Here, the sliding surface is designed to incorporate the desired trolley trajectory while suppressing the sway motion of the payload. To improve the control performance, the discontinuous gain of the sliding control is adjusted with fuzzy logic tuning schemes with respect to the sliding function and its rate of change. Chattering is further reduced by a saturation function. Simulation and experimental results are provided to verify the effectiveness of the proposed control system for offshore container cranes.
\end{abstract}

Keywords: mobile harbor, offshore container crane, anti-sway control, fuzzy sliding mode control.

* Corresponding author 


\section{Introduction}

Cranes are widely used for loading and unloading containers from and to container ships in quay terminals. In recent years, with the rapid increase of world trade as well as the need for larger container ships, shipping companies have resorted to an increase of the vessel size (Pang and Liu, 2014; Steenken et al., 2004). In December 2014, the biggest container ship, the MSC Oscar, with the capacity of 19,224 TEU (twenty-foot equivalent unit) began to operate. Several mega ships over 18,000 TEU are in order and they are expected to be the main operators in various shipping companies. So as to keep up the everincreasing ship sizes, the stevedoring industry has applied several ways to deal with the new trend. One possible option is to improve the efficiency and productivity in cargo handling demands (GarcíaMorales et al., 2015; Ranga Rao and Sundaravadivelu, 1999; Yin et al., 2011). In addition, the container cranes have to become bigger and faster thanks to suitable controllers that can improve the transfer time as well as ensure the safety requirements (Hong and Ngo, 2012). Despite these improvements, many terminals are still faced with two problems: (i) the difficulty in accommodating the mega container ships due to the shallow water depth, and (ii) the port congestion due to the increase of cargo ships. Fortunately though, a special crane-equipped ship, or mobile harbor, capable of open-sea loading and unloading of containers from a large anchored container ship, or mother ship, is a potential solution ( (Ngo and Hong, 2012b).

During the process of loading and unloading containers, the payload oscillations and the method to suppress them to avoid any damage or accidents caused by these oscillations is always the main concern in a container terminal. From the crane control aspect, various control algorithms have been proposed to deal with sway suppression. These methods include open-loop control, such as input shaping control for gantry cranes, bridges (Ngo et al., 2012; Hong et al., 2003; Huey et al., 2008; Robertson and Singhose, 2009; Singhose et al., 2000; Sorensen et al., 2007; Sorensen and Singhose, 2008; Sung and Singhose, 2009a; Sung and Singhose, 2009b), and flexible systems in general (Hong et al., 2003; Huey et al., 2008; Robertson and Singhose, 2009; Singhose et al., 2000; Sorensen et al., 2007; Sorensen and Singhose, 2008; Sung and Singhose, 2009a; Sung and Singhose, 2009b) as well as closed-loop control, such as optimal control (Al-Garni et al., 1995; Hong et al., 2000), state feedback control (Kim et al., 2004; Kłosiński, 2005; Messineo et al., 2008; Park et al., 2007; Sawodny et al., 2002), fuzzy control (Ahmad, 2009; Benhidjeb and Gissinger, 1995; Chang and Chiang, 2008; Chen et al., 2009; Cho and Lee, 2002; Omar et al., 2004), adaptive control (Cheng-Yuan, 2007; Liu et al., 2005; Messineo and Serrani, 2009; Mizumoto et al., 2007; Ngo and Hong, 2012a; Tuan et al., 2013; Yang and Yang, 2007), 
and robust control (Almutairi and Zribi, 2009; Bartolini et al., 2002a, b; Lee, 2004a, b, 2005; Lee et al., 2006; Ngo and Hong, 2012b; Orbisaglia et al., 2008; Xi and Hesketh, 2010).

The conventional control methods developed for offshore container cranes may be unsuitable to mobile harbor cranes due to the effect of sea-excited motions (Ngo and Hong, 2012b). Disturbances such as strong sea waves and gusty winds tend to exacerbate the pendulum oscillations of the crane's hanging load. Therefore, its trolley has to move along a suitable trajectory to compensate for the $\mathrm{MH}$ motion so that the container will be kept in a desired region to guarantee the normal operations of opensea loading and unloading.

For offshore crane control, many researchers have focused on addressing challenges in offshore installations, such as underwater conveying systems for oil and gas field, see e.g., Skaare and Egeland (2006); Messineo and Serrani (2009); and Kuchler et al. (2011). In this context, Hong and Ngo (2012) developed the first mathematical model of the container crane equipped/mounted on a ship with seaexcited motion, whereby a sliding mode control (SMC) strategy was introduced for mobile harbor cranes (Ngo and Hong, 2012b). Robustness of the control system is emphasized by using for offshore boom cranes a second-order sliding mode controller (Raja Ismail and Ha, 2012), and an optimal sliding mode controller (Raja Ismail et al., 2015). In these papers, the system responses were verified through simulations while the trolley trajectory did not take into account compensation for the MH motion in the control strategy. The relationships between waves and ocean structures were also the topics of intense research for other researcher (Cha et al., 2010; Clauss et al., 2009; Do and Pan, 2008; Kyoung et al., 2005; Zhu et al., 2001). In this context, Ngo et al. (2011) first proposed the idea of utilizing the trolley displacement for MH motion compensation, based on a geometric analysis, to not only suppress payload oscillations but also keep the container position in a desired region.

In this paper, by taking advantage of MH motion compensation while enhancing system robustness and control performance, we propose a new control strategy containing these features: (i) path generation to create suitable trajectories for the trolley motion, (ii) prediction mechanism to estimate the influence of the sea motion, and (iii) fuzzy sliding mode control (FSMC) based on the nonlinear model of offshore container cranes (Ngo and Hong, 2012b). According to the prosed strategy, the sliding surface will account for the payload swing, MH motion and also the trolley position to achieve satisfactory system responses in face of disturbances and uncertainties. The control gain, initially having a high value to expedite the reaching phase, can be adjusted during the sliding mode to reduce chattering. Rather than tuning the sliding surface parameters (Ha et al., 1999), the proposed method 
features tuning the discontinuous gain via fuzzy logic inference from information of the sliding function and its rate of change. The sliding function is chosen as a combination of the desired dynamics of the trolley trajectory error and the payload swing angle. Simulation results are provided to show the effectiveness of the control system. Experimental results are also performed on a 6-DOF platform to verify the control performance.

The paper is organized as follows. After the introduction, the offshore container crane dynamics are described in Section 2. The control development is presented in Section 3, consisting of the MH motion compensation, prediction mechanism, and FSMC components, followed by the stability analysis of the closed-loop system. In Section 4, simulation and experimental results of the proposed control system are discussed. Finally, a conclusion is drawn in Section 5.

\section{Dynamic model of an offshore container crane}

The offshore container crane system considered in this paper is mounted on a mobile harbor used to transfer containers from a large mother ship. The arrangement is depicted in Fig. 1(a) while Fig. 1(b) shows three coordinate systems used to derive a dynamic model for the MH crane. Therein, $\left(x_{\mathrm{n}}, y_{\mathrm{n}}, z_{\mathrm{n}}\right)$ is the reference coordinate frame, $\left(x_{\mathrm{s}}, y_{\mathrm{s}}, z_{\mathrm{s}}\right)$ is the $\mathrm{MH}$ coordinate frame with its origin located at its center of gravity, and $\left(x_{\mathrm{t}}, y_{\mathrm{t}}, z_{\mathrm{t}}\right)$ is the trolley coordinate frame affixed to the trolley. Let $m_{\mathrm{t}}$ and $m_{\mathrm{p}}$ be the masses of the trolley and payload, respectively. Let $x$ and $y$ represent respectively the position of the gantry and the trolley in the MH coordinate frame. Let $h$ and $l$ be the crane height and the rope length. Angles $\theta$ and $\delta$ define the longitudinal and lateral sways of the load in the reference coordinate frame, while variables $z, \phi$ and $\psi$ are the heave, roll angle and pitch angle of the mobile harbor, respectively. Finally, let $f_{\mathrm{y}}$ denote the control force applied at the trolley for longitudinal sway control.

To simplify the complex model, let us make the following assumptions: (a) The mass of the rope for suspending the container from the trolley is negligible; (b) The rope length during the operation is slowly time-varying, i.e. $i=0$; (c) Friction in the trolley motion is ignored; and (d) The load is a point mass. By using the Langrangian formulation, the offshore crane system dynamics can be derived as follows (Hong and Ngo, 2012; Ngo and Hong, 2012b): 


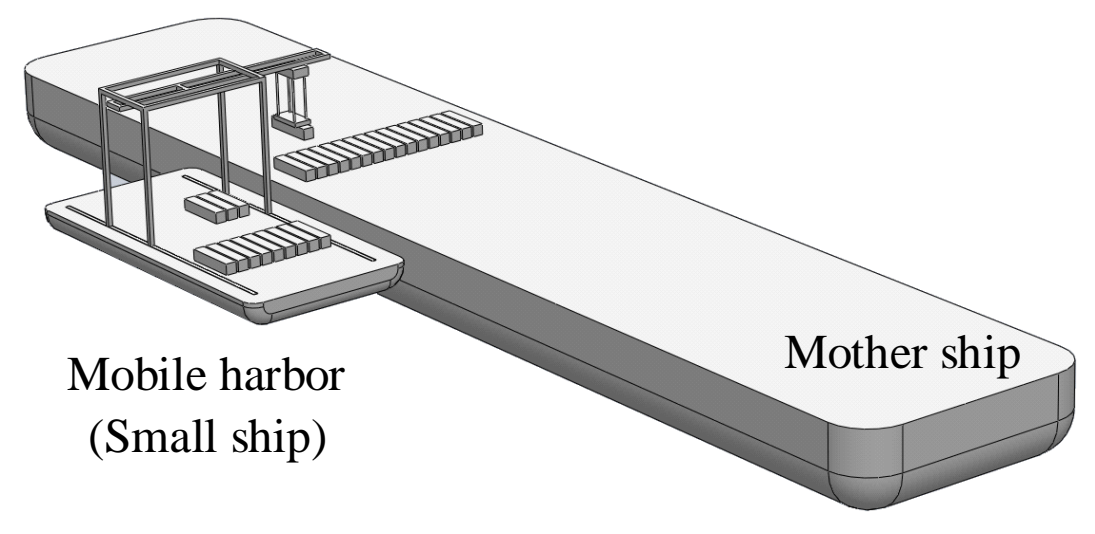

(a) Mother ship and mobile harbor

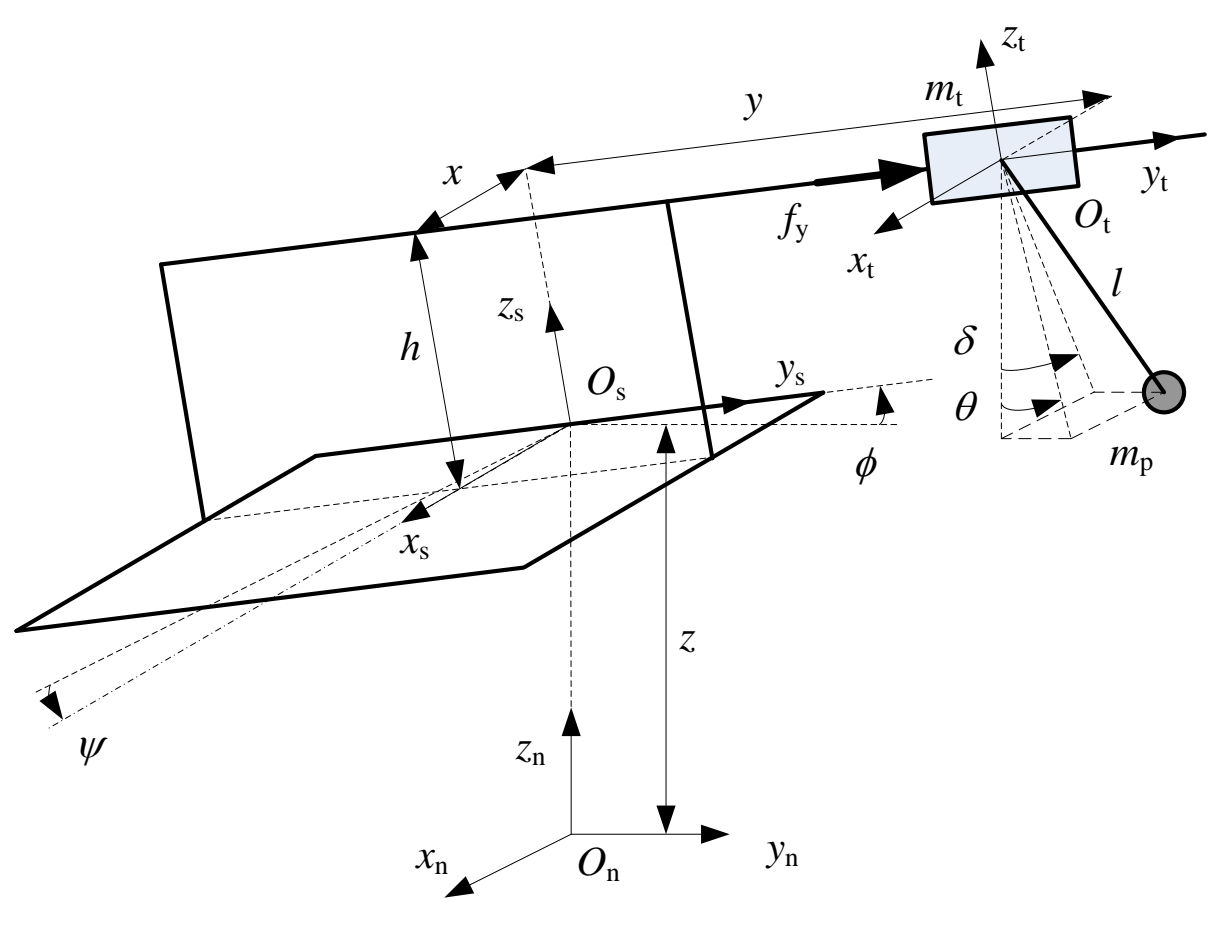

(b) Coordinate frames: reference (mother ship), mobile harbor and trolley

Fig. 1. Offshore crane arrangement and coordinate systems (Hong and Ngo, 2012)

$\left(m_{\mathrm{t}}+m_{\mathrm{p}}\right) \ddot{y}+m_{\mathrm{p}} l \ddot{\theta}(\sin \phi \sin \theta \cos (\delta-\psi)+\cos \phi \cos \theta)+m_{\mathrm{p}} l \ddot{\delta} \sin \phi \cos \theta \sin (\delta-\psi)+c_{1}=f_{\mathrm{y}}$,

$m_{\mathrm{p}}(\sin \phi \sin \theta \cos (\delta-\psi)+\cos \phi \cos \theta) \ddot{y}+m_{\mathrm{p}} l \ddot{\theta}+c_{2}=0$,

$m_{\mathrm{p}} l \ddot{y} \sin \phi \cos \theta \sin (\delta-\psi)+m_{\mathrm{p}} l^{2} \ddot{\delta} \cos ^{2} \theta+c_{3}=0$, 
where

$c_{1}=\left(m_{\mathrm{t}}+m_{\mathrm{p}}\right)\left(-x \ddot{\psi} \sin \phi-h \ddot{\phi}-h \dot{\psi}^{2} \sin \phi \cos \phi\right)+\left(m_{\mathrm{t}}+m_{\mathrm{p}}\right)(g+\ddot{z}) \cos \psi \sin \phi$

$-\left(m_{\mathrm{t}}+m_{\mathrm{p}}\right)\left(\dot{\psi}^{2} \sin ^{2} \phi+\dot{\phi}^{2}\right) y+m_{\mathrm{p}} \ddot{l} \cos \phi \sin \theta-m_{\mathrm{p}} \ddot{l} \sin \phi \cos \theta \cos (\delta-\psi)$

$+2 m_{\mathrm{p}} i \dot{\delta} \sin \phi \cos \theta \sin (\delta-\psi)+2 m_{\mathrm{p}} i \dot{\theta} \sin \phi \sin \theta \cos (\delta-\psi)+2 m_{\mathrm{p}} i \dot{\theta} \cos \phi \cos \theta$

$+m_{\mathrm{p}} l\left(\dot{\theta}^{2}+\dot{\delta}^{2}\right) \sin \phi \cos \theta \cos (\delta-\psi)-m_{\mathrm{p}} l \dot{\theta}^{2} \cos \phi \sin \theta-2 m_{\mathrm{p}} l \dot{\theta} \dot{\delta} \sin \phi \sin \theta \sin (\delta-\psi)$,

$c_{2}=m_{\mathrm{p}}(2 \dot{i} \dot{\theta}+2 \dot{y} \dot{\psi} \sin \phi \sin \theta \sin (\delta-\psi)$

$+2 \dot{y} \dot{\phi} \cos \phi \sin \theta \cos (\delta-\psi)-2 \dot{y} \dot{\phi} \sin \phi \cos \theta+2 y \dot{\psi} \dot{\phi} \cos \phi \sin \theta \sin (\delta-\psi)$

$-2 h \dot{\psi} \dot{\phi} \sin \phi \sin \theta \sin (\delta-\psi)-y \dot{\phi}^{2} \cos \phi \cos \theta-y \dot{\phi}^{2} \sin \phi \sin \theta \cos (\delta-\psi)$

$+h \dot{\phi}^{2} \sin \phi \cos \theta-h \dot{\phi}^{2} \cos \phi \sin \theta \cos (\delta-\psi)-y \dot{\psi}^{2} \sin \phi \sin \theta \cos (\delta-\psi)$

$-x \dot{\psi}^{2} \sin \theta \sin (\delta-\psi)-h \dot{\psi}^{2} \cos \phi \sin \theta \cos (\delta-\psi)-x \ddot{\psi} \sin \theta \cos (\delta-\psi)$

$+y \ddot{\psi} \sin \phi \sin \theta \sin (\delta-\psi)+h \ddot{\psi} \cos \phi \sin \theta \sin (\delta-\psi)-h \ddot{\phi} \cos \phi \cos \theta$

$-h \ddot{\phi} \sin \phi \sin \theta \cos (\delta-\psi)+y \ddot{\phi} \cos \phi \sin \theta \cos (\delta-\psi)-y \ddot{\phi} \sin \phi \cos \theta$

$\left.+l \dot{\delta}^{2} \sin \theta \cos \theta+(g+\ddot{z}) \sin \theta \cos \delta\right)$,

$c_{3}=m_{\mathrm{p}} l\left(-2 l \dot{\delta} \dot{\theta} \sin \theta \cos \theta+2 i \dot{\delta} \cos ^{2} \theta+2 \dot{y} \dot{\varphi} \cos \varphi \cos \theta \sin (\delta-\psi)\right.$

$-2 \dot{y} \dot{\psi} \sin \varphi \cos \theta \cos (\delta-\psi)-y \ddot{\psi} \sin \varphi \cos \theta \cos (\delta-\psi)$

$+y \ddot{\varphi} \cos \varphi \cos \theta \sin (\delta-\psi)-y\left(\dot{\varphi}^{2}+\dot{\psi}^{2}\right) \sin \varphi \cos \theta \sin (\delta-\psi)$

$-2 y \dot{\psi} \dot{\varphi} \cos \varphi \cos \theta \cos (\delta-\psi)-h \ddot{\psi} \cos \varphi \cos \theta \cos (\delta-\psi)$

$-h \ddot{\varphi} \sin \varphi \cos \theta \sin (\delta-\psi)-h\left(\dot{\varphi}^{2}+\dot{\psi}^{2}\right) \cos \varphi \cos \theta \sin (\delta-\psi)$

$+2 h \dot{\psi} \dot{\varphi} \sin \varphi \cos \theta \cos (\delta-\psi)-x \ddot{\psi} \cos \theta \sin (\delta-\psi)$

$\left.+x \dot{\psi}^{2} \cos \theta \cos (\delta-\psi)+(g+\ddot{z}) \cos \theta \sin \delta\right)$,

where specifications are shown in Fig. 1(b) and $g$ is the gravitational acceleration.

\section{Fuzzy sliding mode control for anti-sway offshore stevedoring}

This section presents the control development for trajectory tracking and anti-sway control of the $\mathrm{MH}$ crane. The system block diagram is shown in Fig. 2, featuring an anti-sway controller with path generation and prediction mechanism blocks. In this paper, only the $\mathrm{MH}$ roll motion is considered, given the sufficiently large size of the mobile harbor (Hong and Ngo, 2012). The MH motion is subject to measurement noise $d(t)$ to be taken into account during the control design and verification. 


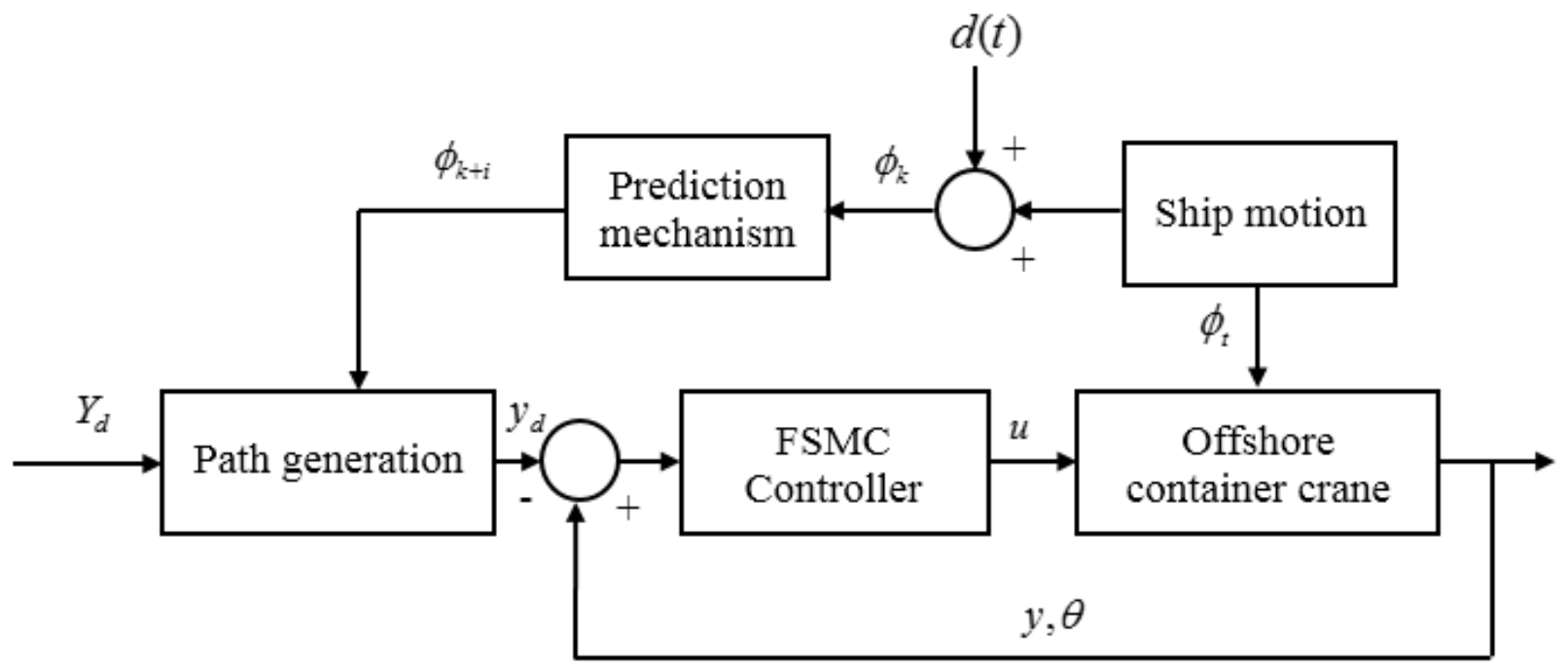

Fig. 2. Block diagram of the proposed control system.

\subsection{Trajectory generation}

During loading and unloading process, it is required to keep the container in the desired position under the influence of the roll motion of $\mathrm{MH}$. To satisfy this requirement, the trolley has to follow a specified trajectory so that the payload position in the reference coordinate remains constant, i.e. $Y_{d}$. This trajectory, $y_{d}(t)$, can be obtained as follows (Ngo et al., 2011):

$y_{d}(t)=\frac{Y_{d}+h \sin \phi(t)}{\cos \phi(t)}$

\subsection{Prediction algorithm}

The desired trajectory of the trolley is generated from information of the MH's roll angle, $\phi(t)$. To predict this motion, a Kalman filter is used and described by the following equations:

$\Phi_{k+1}=A \Phi_{k}+\varpi_{k}$

$y_{k}=\hat{\phi}_{k}=H \Phi_{k}+v_{k}$,

where $\Phi_{k}=\left(\phi_{k}, \dot{\phi}_{k}, \ddot{\phi}_{k}\right)^{T}, A$ and $H$ are respectively the state transition and observation output matrices, $\varpi_{k}=\left(w_{k}, \dot{w}_{k}, \ddot{w}_{k}\right)^{T}$ represents the process noise, and $v_{k}$ is the measurement noise of the system. Let the 
filter output be the estimate of the $\mathrm{MH}$ roll angle and given a sampling time $T_{s}$ of the system, matrices $A$ and $H$ can be written in the following form based on first-order differences (Janabi-Sharifi et al., 2000):

$$
A=\left[\begin{array}{ccc}
1 & T_{s} & \frac{T_{s}^{2}}{2} \\
0 & 1 & T_{s} \\
0 & 0 & 1
\end{array}\right], H=\left[\begin{array}{lll}
1 & 0 & 0
\end{array}\right]
$$

Then, the discrete-time Kalman algorithm comprising the prediction and update steps is described by the following equations:

- Prediction:

$\hat{\Phi}_{k, k-1}=A \hat{\Phi}_{k-1, k-1}$,

$P_{k, k-1}=A P_{k-1, k-1} A^{T}+Q_{k}$,

- Update:

$K_{k}=P_{k, k-1} H_{k}^{T}\left[r_{k}+H_{k} P_{k, k-1} H_{k}^{T}\right]^{-1}$

$\hat{\Phi}_{k, k}=\hat{\Phi}_{k, k-1}+K_{k}\left[y_{k}-H_{k} \hat{\Phi}_{k, k-1}\right]$

$P_{k, k}=P_{k, k-1}-K_{k} H_{k} P_{k, k-1}$,

where $P, Q$ and $r$ are respectively the estimation error covariance, process noise covariance and measurement error covariance. From the roll angle estimate in the first step, the next impact of the sea wave motion to the MH can be obtained.

\subsection{Control algorithm}

In this section, an anti-sway control scheme is proposed based on the fuzzy sliding mode control. As mentioned previously, the lateral sway is not considered thanks to mother ship's mega size, thus only the trolley position $y$ and longitudinal sway $\theta$ are to be controlled. Therefore, in order to decouple the under-actuated and actuated dynamics, equations (1) and (2) are combined by eliminating $\ddot{\theta}$. Thus, the crane dynamics can be rewritten in the state space form as follows:

$$
M(q) \ddot{q}+W(q, \dot{q})=u,
$$


where

$q=[y], M(q)=\left[m_{11}\right], W(q, \dot{q})=\left[w_{11}\right], u=\left[f_{y}\right]$

$m_{11}=\left(m_{t}+m_{p}\right)-m_{p}(\sin \phi \sin \theta \cos (\delta-\psi)+\cos \phi \cos \theta)^{2}$,

and $w_{11}=c_{1}-c_{2}(\sin \phi \sin \theta \cos (\delta-\psi)+\cos \phi \cos \theta)$.

To control both the trolley motion and the swing angle, the error vector is defined as follow:

$e(t)=\left[e_{y}(t) \quad e_{\theta}(t)\right]^{T}=\left[\begin{array}{ll}y(t)-y_{d}(t) & \theta(t)\end{array}\right]^{T}$,

where $y_{d}(t)$ is the desired trolley position and $\theta(t)=\theta^{*}+\phi(t)$, in which $\theta^{*}$ is the payload swing value obtained through an encoder. The desired sway angle is obviously set at zero. Moreover, without loss of generality, let us assume that the first and second time derivatives of the trolley reference are bounded and $l$ is different from zero.

In this paper, the sliding function $s$, combining the desired trolley motion and swing dynamics taking into account the MH motion, is adopted from Ngo \& Hong (2012a) as follows:

$s=\dot{e}_{y}+k_{1} e_{y}-k_{2} \theta$

where $k_{1}$ and $k_{2}$ are positive constants. The following FSMC law is proposed:

$u=M(q)[\eta(t)-\kappa(t) \operatorname{sgn}(s)]+W(q, \dot{q})$,

where $\eta(t)=\ddot{y}_{d}-k_{1} \dot{e}_{y}+k_{2} \dot{\theta}$ and the discontinuous gain $\kappa(t)$ is defined as follows:

$\kappa(t)=\left\{\begin{array}{l}K \text { if }|s|>\varepsilon>0 \\ \hat{k}(t) \text { if }-\varepsilon \leq s \leq \varepsilon,\end{array}\right.$

in which $K>0$ is a sufficiently large gain to induce a sliding mode, $\varepsilon$ is a small positive constant for a boundary layer, and $\hat{k}(t)$ is an adjustable gain to be tuned by fuzzy logic schemes.

\subsection{Fuzzy rule for control gain tuning}

In this proposed controller, the ranges for $s(t), \dot{s}(t)$ and $\hat{k}(t)$ are respectively $\left[\begin{array}{ll}-0.3 & 0.3\end{array}\right]$, [ $\left.\begin{array}{ll}-2 & 2\end{array}\right]$ and $\left[\begin{array}{ll}10 & 40\end{array}\right]$. Five fuzzy sets, namely NB (negative big), NM (negative medium), ZE (zero), PM 
(positive medium), and PB (positive big) are chosen for $s(t)$ and $\dot{s}(t)$ while five other fuzzy sets, PVS (positive very small), PS (positive small), PM (positive medium), PB (positive big), and PVB (positive very big) are selected for $\hat{k}(t)$, all with triangle membership functions, as shown in Fig. 3. The fuzzy rule for tuning the control gain is expressed generally as:

$R^{k}$ : If $\left(s(t)\right.$ is $\left.A^{k}\right)$ and $\left(\dot{s}(t)\right.$ is $\left.B^{k}\right)$ then $\left(\hat{k}(t)\right.$ is $\left.C^{k}\right)$,

where $A^{k}, B^{k}$, and $C^{k}$ are fuzzy sets of $s(t), \dot{s}(t)$ and $\hat{k}(t)$, respectively; $k=1, \ldots, n$ represents the rule index. Since we have five fuzzy sets for two inputs $s(t)$ and $\dot{s}(t)$, the total rule number is $k=25$ fuzzy rules, as given im Table 1.

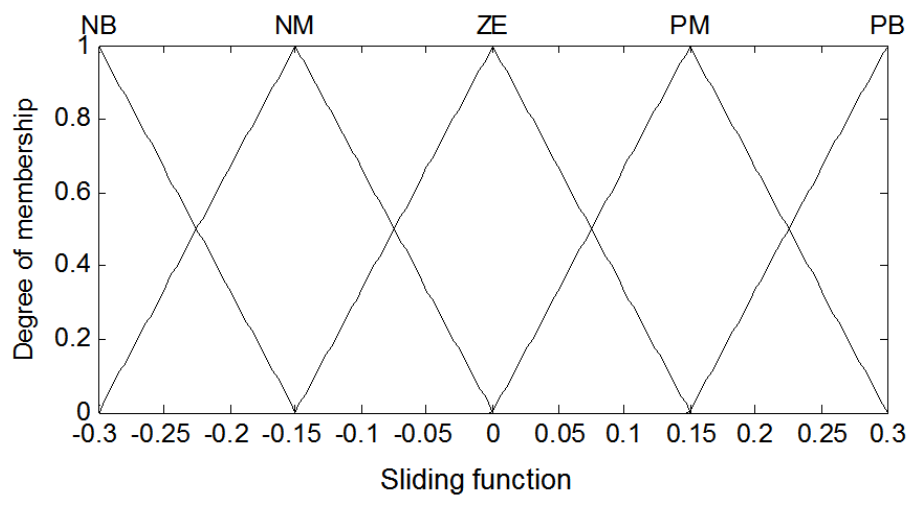

(a) Sliding function

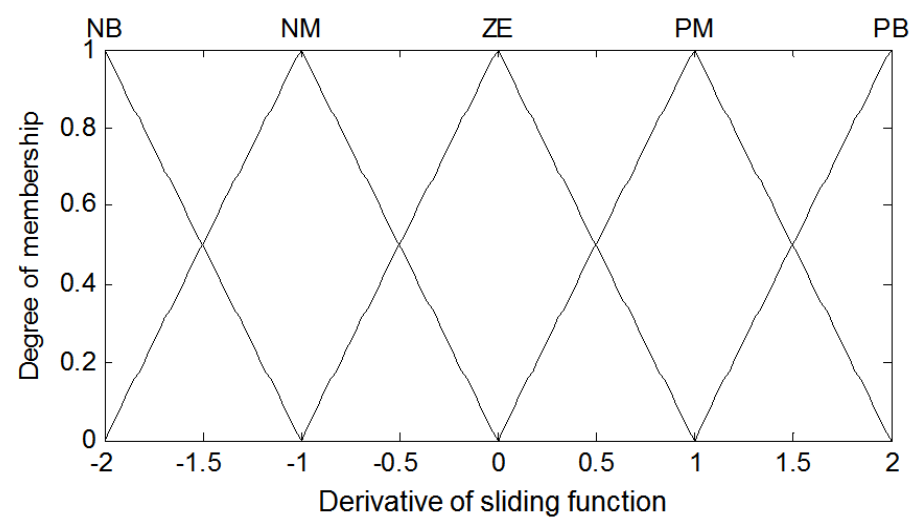

(b) Sliding function rate of change 


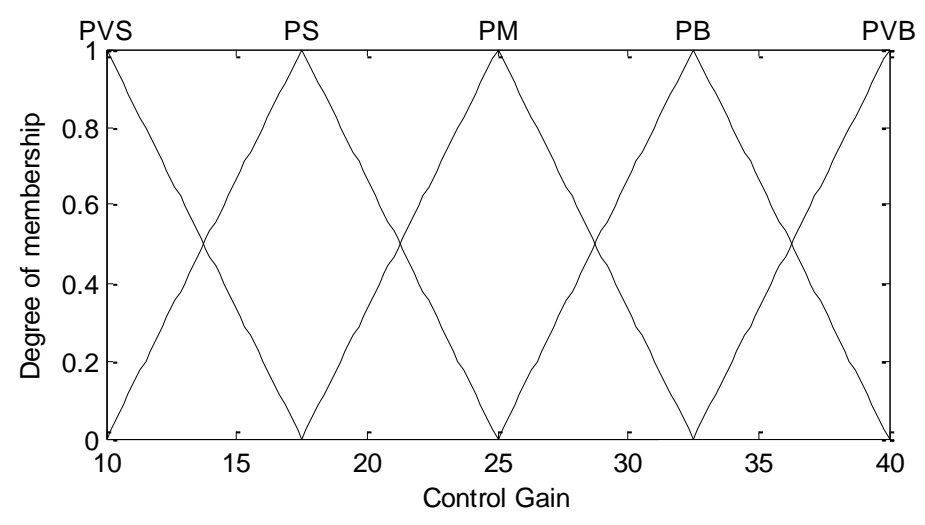

(c) Control gain

Fig. 3. Membership functions.

Table 1. Fuzzy rules for gain tuning.

\begin{tabular}{|c|c|c|c|c|c|c|}
\hline \multirow{7}{*}{ 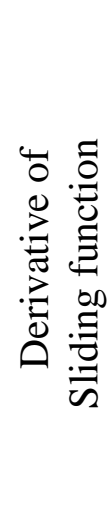 } & \multicolumn{6}{|c|}{ Sliding function } \\
\hline & & NB & NM & $\mathrm{ZE}$ & PM & PB \\
\hline & NB & PVB & PB & $\mathrm{PB}$ & PS & PVS \\
\hline & NM & PB & PM & PM & PVS & PS \\
\hline & $\mathrm{ZE}$ & PB & PM & PVS & PM & $\mathrm{PB}$ \\
\hline & PM & PS & PVS & PM & PM & $\mathrm{PB}$ \\
\hline & PB & PVS & PS & $\mathrm{PB}$ & PB & PVB \\
\hline
\end{tabular}

\subsection{Stability analysis}

In our development, $s$ and $\dot{s}$ are controlled in such a way that $s, \dot{s} \rightarrow 0$ asymptotically as $t \rightarrow \infty$. Then, the control law (12) guarantees that $e, \dot{e} \rightarrow 0$ asymptotically for all time $t \geq t_{1}$ with some finite time $t_{1}$. This implies that asymptotic stability of the offshore container crane system can be achieved by proving the asymptotic stability of the sliding surface $s$. Indeed, to prove the stability of the system by means of control algorithm (12), a positive Lyapunov function is considered as follows.

$V(t)=\frac{1}{2} s^{2}$

Differentiation of the Lyapunov function yields: 
$\dot{V}(t)=s \dot{s}$

Substitution of (10) and (11) into (16) yields:

$\dot{V}(t)=s\left(\ddot{y}-\ddot{y}_{d}+k_{1} \dot{e}_{y}-k_{2} \dot{\theta}\right)$.

By using (9), (17) can be rewritten as:

$\dot{V}(t)=s\left(M^{-1}(q)(-W(q, \dot{q})+u)-\ddot{y}_{d}+k_{1} \dot{e}_{y}-k_{2} \dot{\theta}\right)$.

Hence, from the proposed control law (12), the derivative of the Lyapunov function becomes:

$\dot{V}(t)=-s \kappa(t) \operatorname{sgn}(s)=\left\{\begin{array}{l}-K|s|<0 \text { if }|s|>\varepsilon \\ -\hat{k}(t)|s| \leq 0 \text { otherwise, }\end{array}\right.$

which implies that the surface $s=0$ is reached globally in finite time. From the definition (11), we have on the sliding surface:

$\dot{e}_{y}=-k_{1} e_{y}+k_{2} \theta$

$\ddot{e}_{y}=-k_{1} \dot{e}_{y}+k_{2} \dot{\theta}$

By substituting (21) into (9) and using linear approximations $\cos \theta \approx 1, \sin \theta \approx \theta$ around the equilibrium, we can obtain:

$l \ddot{\theta}+k_{2} \dot{\theta}+\left(g-k_{1} k_{\theta}\right) \theta+k_{1}^{2} e_{y}=0$.

Equations (20) and (22) form a new dynamical system

$$
\left[\begin{array}{l}
\dot{z}_{1} \\
\dot{z}_{2} \\
\dot{z}_{3}
\end{array}\right]=\left[\begin{array}{ccc}
-k_{1} & k_{2} & 0 \\
0 & 0 & 1 \\
-\frac{k_{1}^{2}}{l} & -\frac{g-k_{1} k_{2}}{l} & -\frac{k_{2}}{l}
\end{array}\right]\left[\begin{array}{l}
z_{1} \\
z_{2} \\
z_{3}
\end{array}\right],
$$

where $z_{1}=e_{y}, z_{2}=\theta$, and $z_{3}=\dot{\theta}$, of which the characteristic equation can be obtained as follows.

$$
p^{3}+\left(\frac{k_{2}}{l}+k_{1}\right) p^{2}+\frac{g}{l} p+\frac{g k_{1}}{l}=0
$$

where $p$ is a complex variable. It can be easily verified that the equilibrium of the system is stable, i.e. the polynomial in the left side of (24) is Hurwitz, if $k_{1}>0$ and $k_{2}>0$. Therefore, with the choice of the 
control law (12) where $k_{1}>0$ and $k_{2}>0$, the trolley error $e_{y}$, sway angle $\theta$, and $\dot{\theta}$ tend to zero as $t$ goes to infinity.

Remark: To avoid the chattering phenomenon induced by the term $\operatorname{sgn}(s)$ in control law (12), a saturation function $\operatorname{sat}(s, \lambda)$ can be used instead:

$$
\operatorname{sat}(s, \lambda)=\left\{\begin{array}{ccc}
s / \lambda, & \text { if } & |s| \leq \lambda \\
\operatorname{sgn}(s, \lambda), & \text { if } & |s|>\lambda
\end{array}\right.
$$

where $\lambda$ is a small positive constant.

\section{Simulation and experimental results}

The crane set-up includes of two subsystems: a six degree-of-freedom (6DOFs) platform to generate the MH motion induced by random sea waves and a three-dimensional (3D) crane. Various sensors and actuators are installed for data acquisition and efficient positioning of the payload. The trolley system is driven, via a belt mechanism, by a DC motor equipped with encoders for measuring the trolley position. In addition, readings of the payload rotational movement are also obtained by encoders. To measure the motion of platform (MH motion), an inertial measurement unit (IMU) of type MPU 6050 is used.

\subsection{Simulation results}

The parameter values of the crane system are listed as: the trolley mass $m_{t}=4.5 \mathrm{~kg}$, the payload mass $m_{p}$ $=1 \mathrm{~kg}$, the rope length $l=0.7 \mathrm{~m}$, and the crane height $h=1 \mathrm{~m}$, while the gravitational gravity is $g=$ $9.81 \mathrm{~m} / \mathrm{s}^{2}$. The covariance for the Kalman filter design are selected as $Q=\left[\begin{array}{llllllll}0.1 & 0 & 0 ; 0 & 20 & 0 ; 0 & 0 & 10000\end{array}\right]$ and $r=1$, chosen from the tolerance of the IMU sensor, and from trial and error. The sampling period is $T_{s}=0.01 \mathrm{~s}$. The sliding function parameters are chosen as $k_{1}=1.83, k_{2}=2.5$, depending on how fast the trolley error $e_{y}$ and the sway angle $\theta$ are driven to zero. The control gain $K$ and boundary layer width $\varepsilon$ are selected respectively as 45 and 0.3 for a good compromise between robustness and control chattering. The roll motion of mobile harbor is taken as sinusoidal with $\phi=0.02 \sin 1.25 t$, adopting the ocean wave's movement (Ngo and Hong, 2012b).

Several control situations are considered to illustrate performance of the proposed control strategy in different scenarios. The first one is by considering that the mobile harbor is free from roll motion 
$(\phi=0)$. In this case, the trolley reached the goal position set at $0.5 \mathrm{~m}$ in $2.5 \mathrm{~s}$ without any residual sway, as shown in Fig. 4.

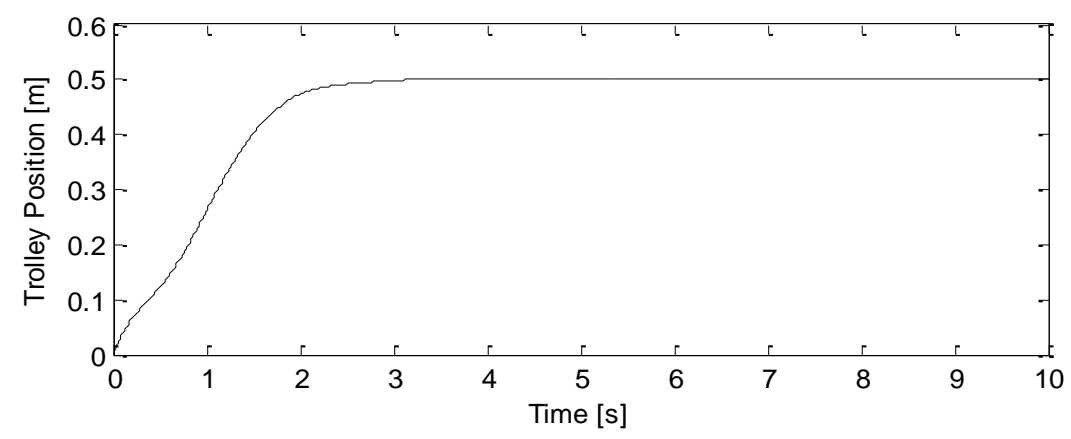

(a) Trolley movement

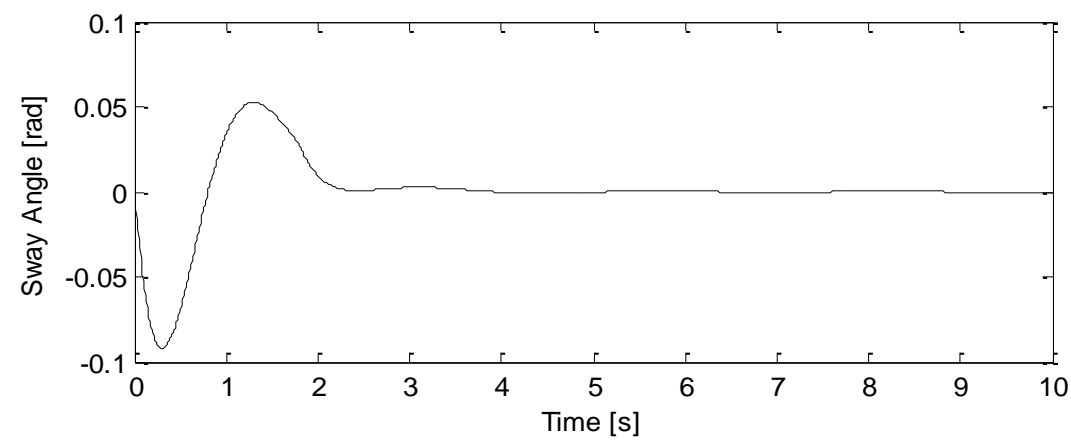

(b) Sway angle

Fig. 4. Trolley movement and sway angle of the payload load without roll motion.

The second scenario considers the MH's roll motion, assumed to be sinusoidal with $\phi=0.02 \sin 1.25 t$ as depicted in Fig. 5(a) for the case without measurement noise. As shown in Fig. 5(b) and (c), the payload motion under the proposed FSMC is restricted within a small region of $(-0.02 \mathrm{~m} ; 0.02 \mathrm{~m})$ while the swing motion is also kept in a band of $0.01 \mathrm{rad}$ (0.6 degree), which is much smaller than an allowable range for the crane residual sway.

The control performance also remains very good when the crane model is subject to a white noise of up to $15 \%$ in the measurement of the MH's roll motion, as shown in Fig. 6, with the payload motion remaining in the region $(-0.04 \mathrm{~m} ; 0.04 \mathrm{~m})$ and the sway oscillations magnitude being less than $0.05 \mathrm{rad}$ (2.9 degrees).

In order to test robustness of the proposed controller, the rope length is set to fluctuate around $\pm 28 \%$ its the nominal value. Cases when the crane's rope length is reduced to $0.5 \mathrm{~m}$ and increased to $0.85 \mathrm{~m}$ are 
considered as shown in Figs. 7 and 8. As can be observed therein, the responses of the payload position and the sway angle appear to be insensitive to the rope length variations in both cases.

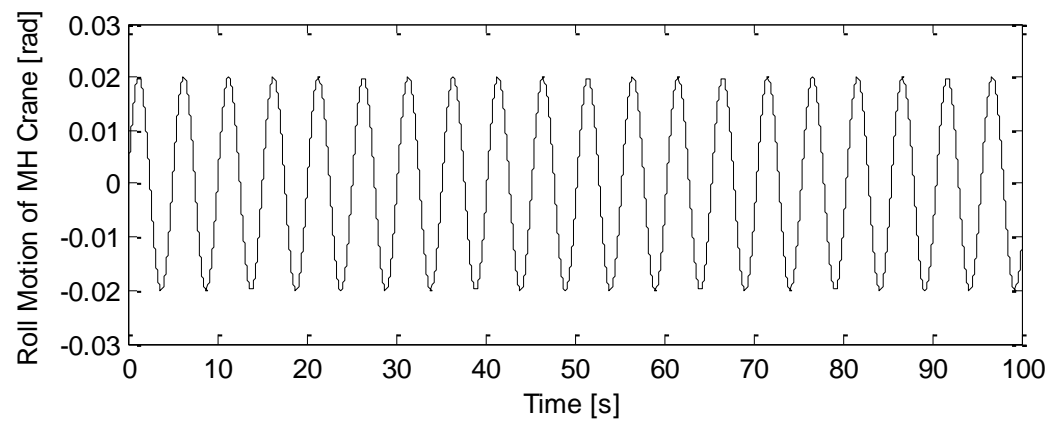

(a) Roll motion of the MH without noise

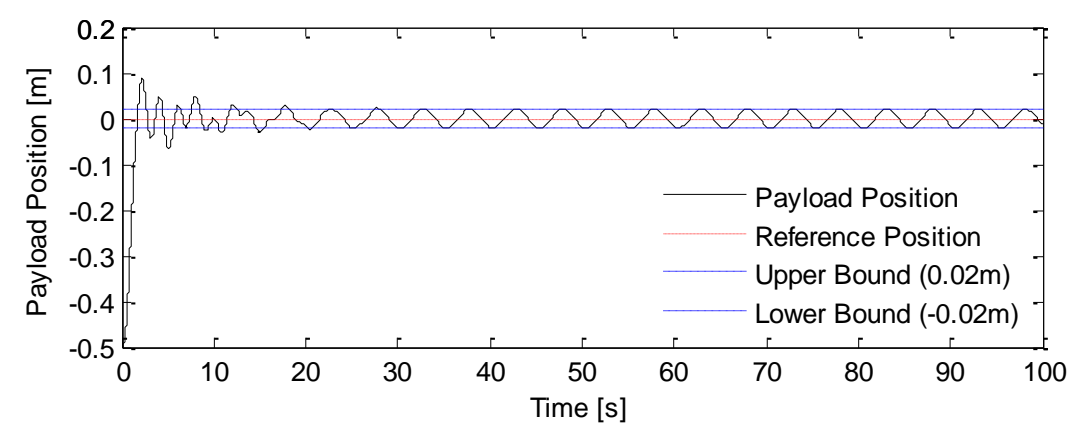

(b) Payload position

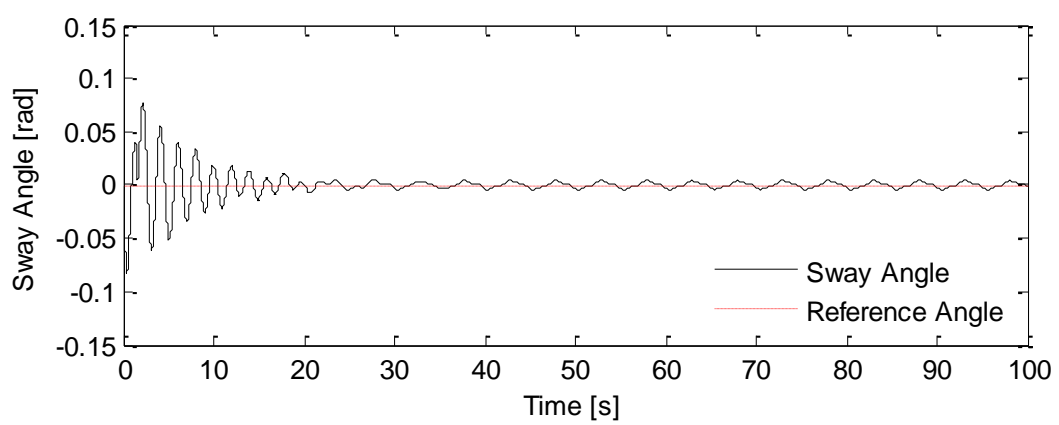

(c) Sway angle

Fig. 5. Control performance at $\phi=0.02 \sin 1.25 t$, without measurement noise. 


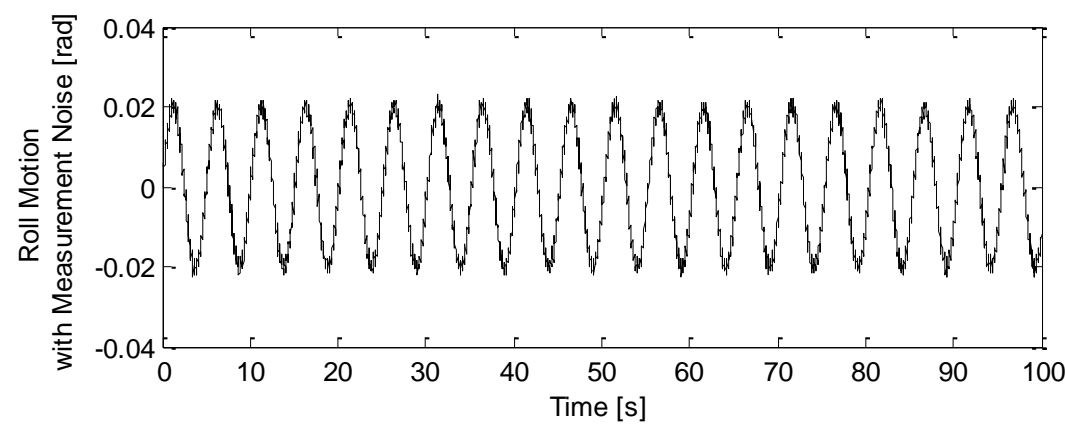

(a) Roll motion of the $\mathrm{MH}$ with white noise in the measurement

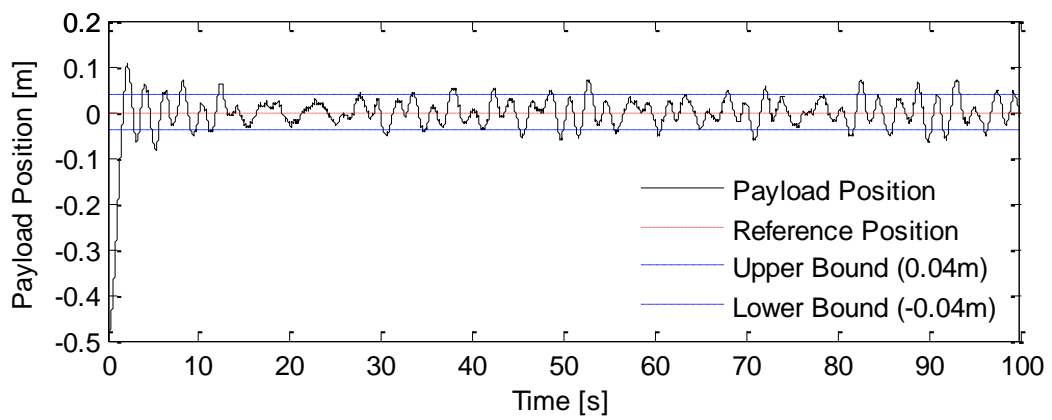

(b) Payload position

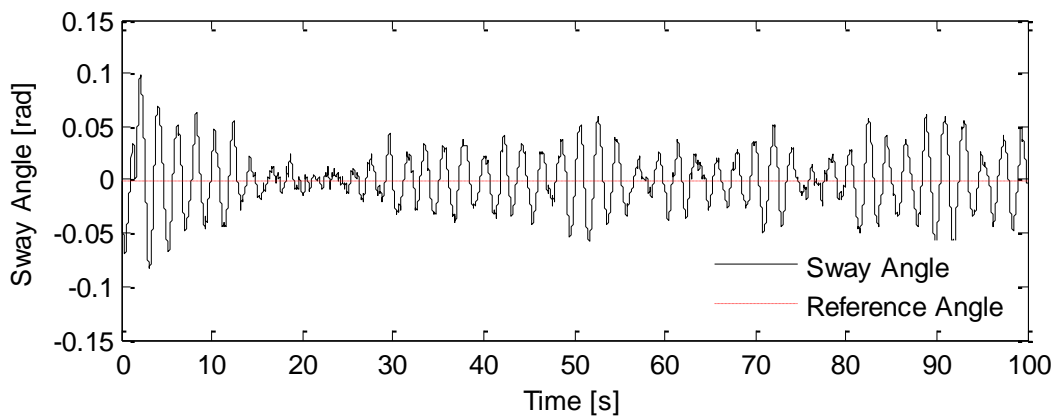

(c) Sway angle

Fig. 6. Control performance at $\phi=0.02 \sin 1.25 t$, with measurement white noise. 


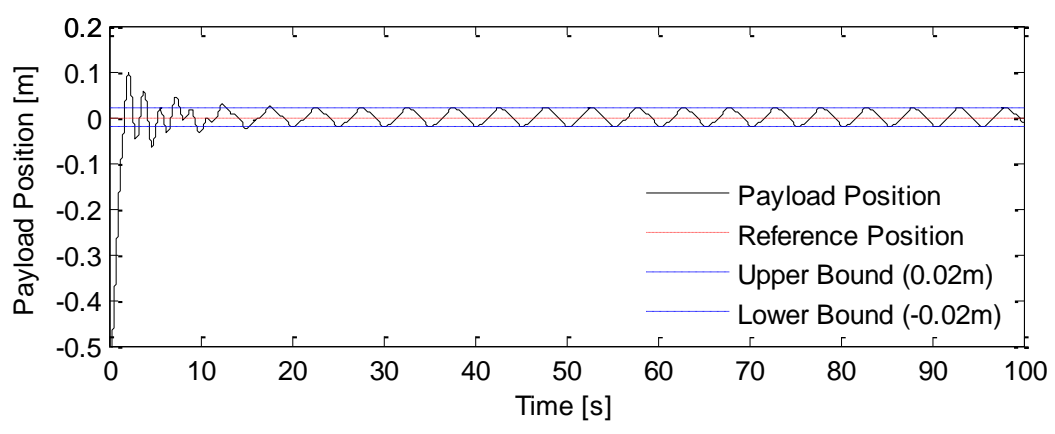

(a) Payload position

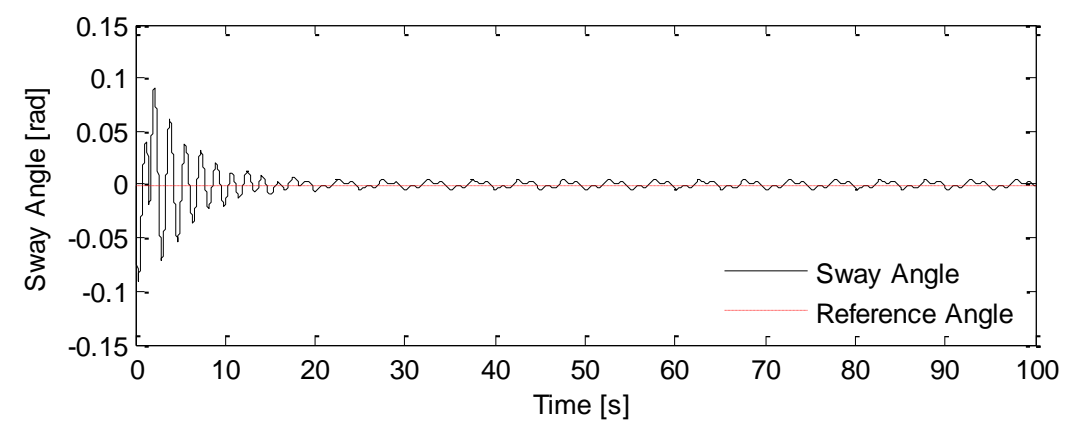

(b) Sway angle

Fig. 7. Control performance- rope length reduced to $0.5 \mathrm{~m}$.

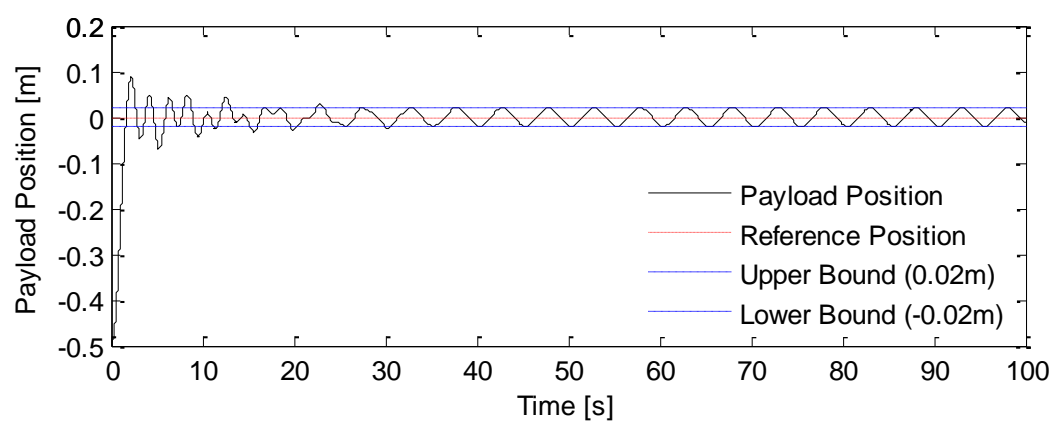

(a) Payload position

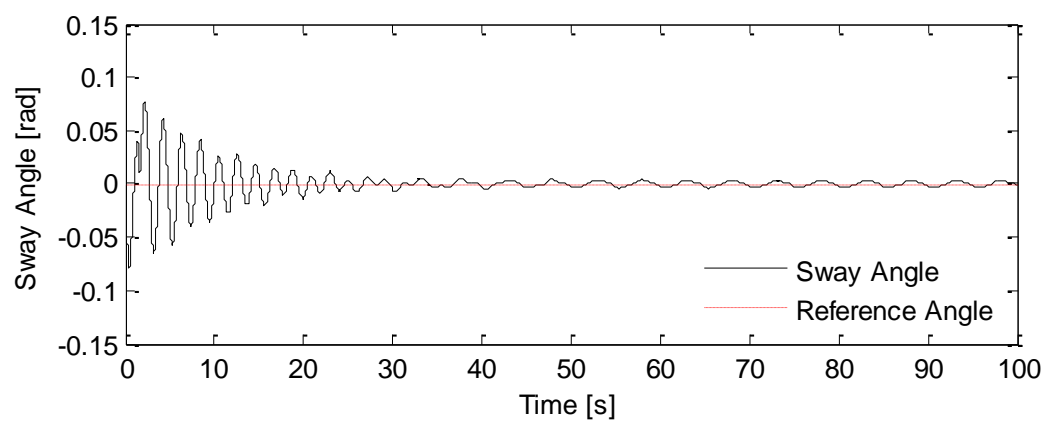

(b) Sway angle

Fig. 8. Control performance- rope length increased to $0.85 \mathrm{~m}$. 


\subsection{Experiment verification}

The test rig is shown in Fig. 9(a), where the 3D crane is placed on top of a programmable 6-DOF platform used to emulate the MH motion. Here, the crane model's rope length can be adjusted by using another DC motor through the hoist system with the container being hung via a single wire for simplicity. The 6-DOF platform provides the emulated MH motion, which is generated from the roll angle record, obtained by applying the Marine Systems Simulator (MSS) toolbox (Perez \& Fossen, 2009) to the crane model. This waveform for the roll motion of the platform as measured from IMU is shown in Fig. 9(b).

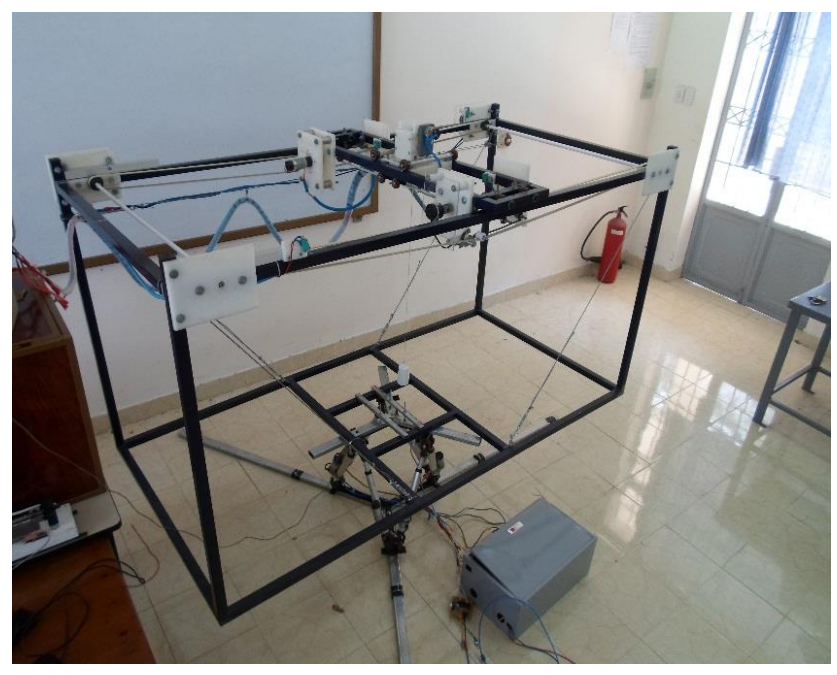

(a) The setup: 6 DOF platform and 3D crane.

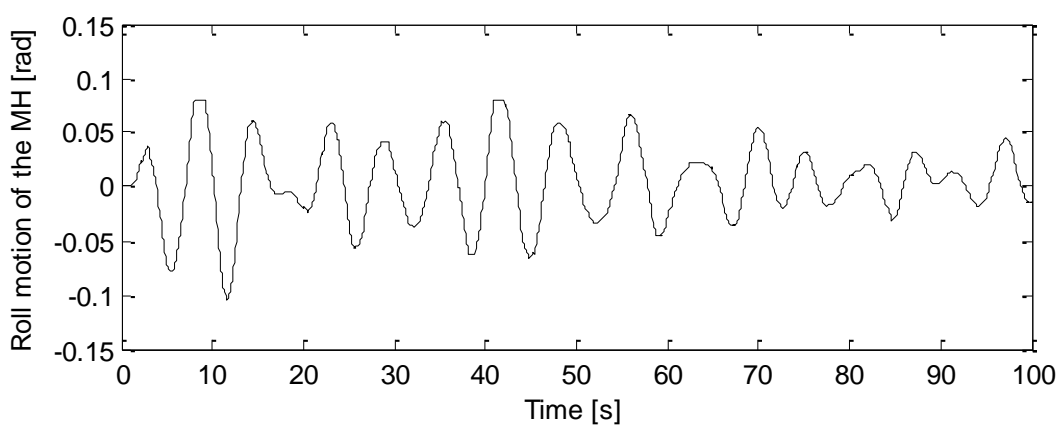

(b) Experimental roll angle.

Fig. 9. Test rig and wave-induced motion of the mobile harbor

Experiments were performed for suppressing the sway angle and keeping the payload in the desired position. The container will be controlled to move laterally $0.5 \mathrm{~m}$ from its initial position under the proposed FSMC with the same set of control parameters as given in Section 4.1 above. To verify the 
control performance, in particular, to illustrate the idea of generating the trolley' desired trajectory for compensation of the wave-induced $\mathrm{MH}$ vibrations, several scenarios were studied in the experiments, whereby the proposed control strategy is compared to the case of using only a sliding mode controller (SMC), with and without Kalman filter-based prediction of the MH roll motion.

\section{Case 1: No roll motion of the mobile harbor $(\phi=0)$}

First we verify the merit of FSMC when the platform is stationary, i.e., no roll motion, $\phi=0$. Responses of the trolley and the sway angle are shown in Fig. 10, where it can be seen that both controllers are adequate to restrain the swing motion with the proposed strategy outperforming the SMC in taking about only 2 seconds to reach the reference destination.

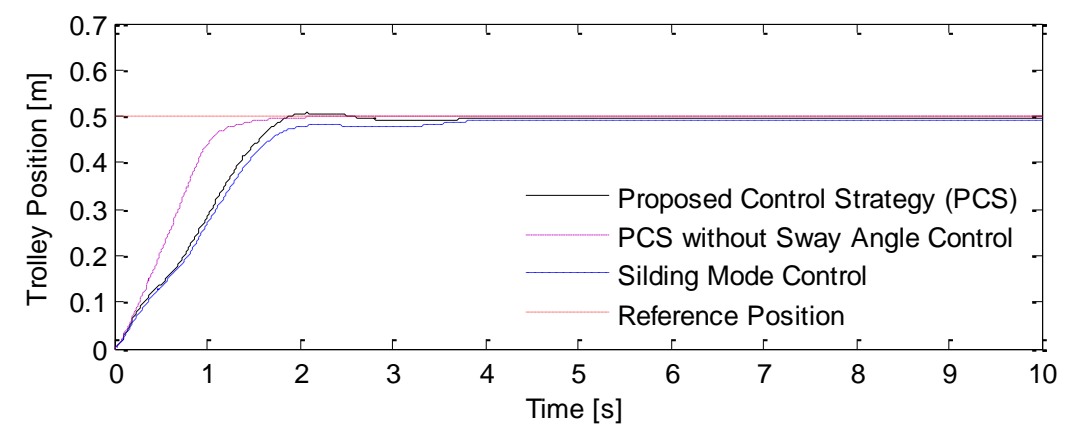

(a) Trolley movement

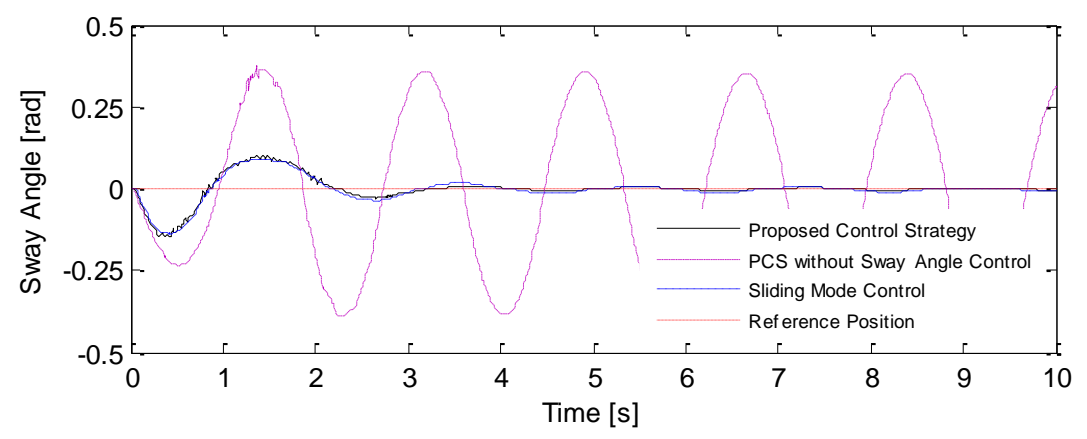

(b) Sway angle

Fig. 10. Experimental results - No roll motion.

\section{Case 2: With MH motion but no compensation}

The second scenario in the investigation is considered to test the case when the platform is subject to the wave-induced MH roll motion shown in Fig. 9(b). Under SMC, i.e. without compensation for the MH 
motion from Kalman filter-based prediction of the roll angle, one can find that the trolley tends to follow the sway trend, leading to large oscillations of the payload position in the range of $(-0.05 \mathrm{~m} ; 0.05 \mathrm{~m})$ around the set-point, as shown in Fig. 11. This situation can be improved by tuning the discontinuous gain in the FSMC alone, i.e., without compensation of the MH motion. Control performance of the implemented FSMC is shown in Fig. 12, where one can find that the payload position is now restrained in the settling band $(-0.023 \mathrm{~m} ; 0.023 \mathrm{~m})$ while the sway angle displays an oscillatory but acceptable. The control performance can be further improved with the trolley following a desired trajectory generated from the MH roll motion estimation via Kalman filtering, as described in Case 3.

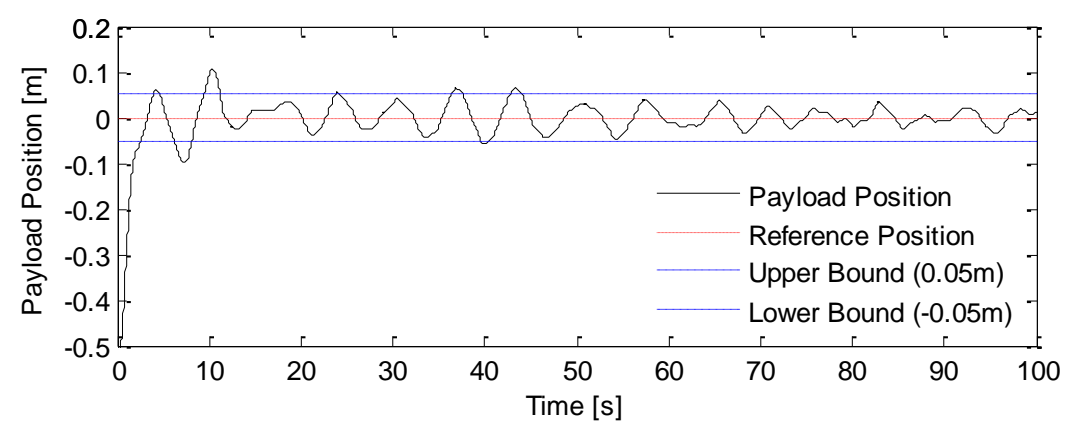

(a) Payload position.

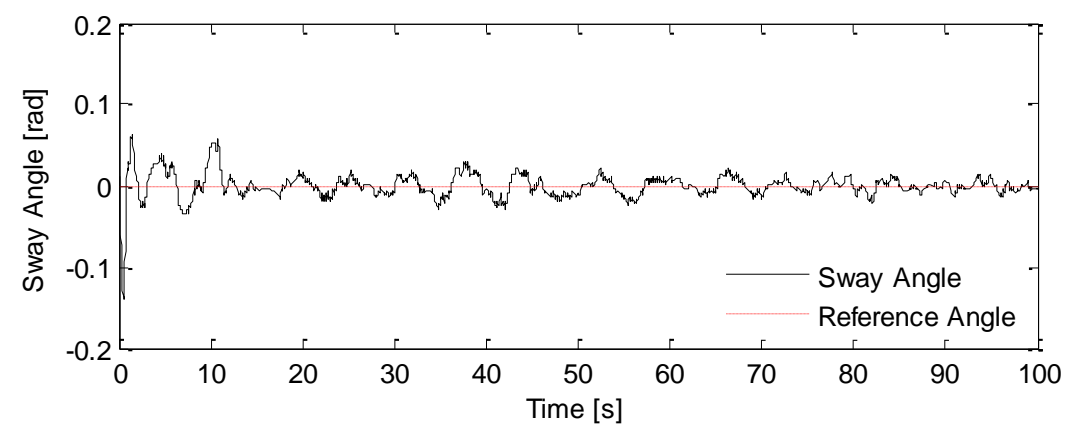

(b) Sway angle.

Fig. 11. Experimental results with $\mathrm{MH}$ roll motion under SMC.

\section{Case 3: With MH motion and compensation from roll angle prediction}

The merit of the proposed control strategy is shown in Fig. 13, whereby the prediction algorithm in (7) and (8) is applied to generate the trolley's desired reference for compensation of the $\mathrm{MH}$ roll motion due to the ocean waves. One can find that the payload position is kept in a small band of $(-0.02 \mathrm{~m} ; 0.02 \mathrm{~m})$ after reaching its desired position while the swing motion of container is further restrained, as shown in 
Fig. 13(a) and (b). Notably, chattering commonly-associated with SMC has been almost avoided in the proposed controller, as can be observed from the sliding function and control gain in Fig. 13(c) and (d).

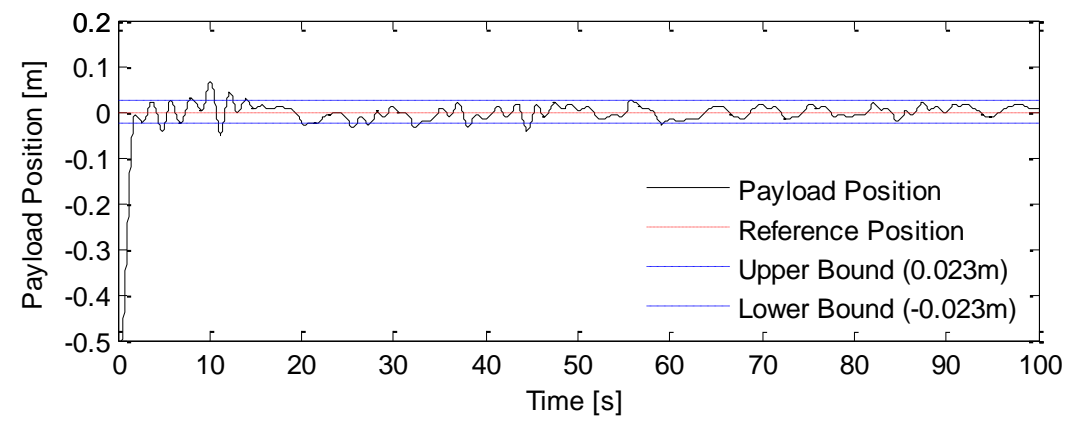

(a) Payload position.

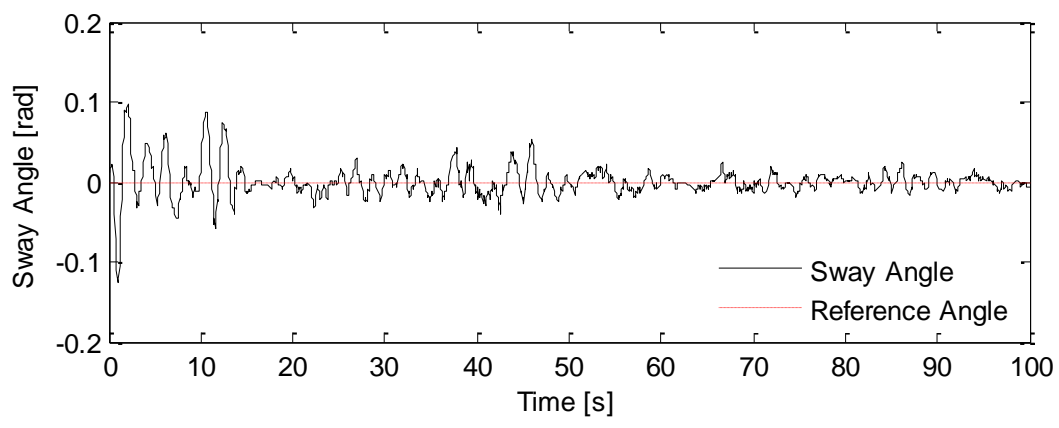

(b) Sway angle.

Fig. 12. Experimental results with $\mathrm{MH}$ roll motion under FSMC without MH motion compensation.

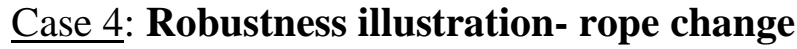

To illustrate the robust performance of proposed control strategy, the offshore crane model is now subject to a rope length variation of around $\pm 28 \%$ from its nominal value. In both decreasing and increasing cases of the rope length, the payload (container) still maintains within the desired region while the sway angle remains within a small range, unperturbed by the rope length variations, as shown respectively in Figs. 14 and 15. 


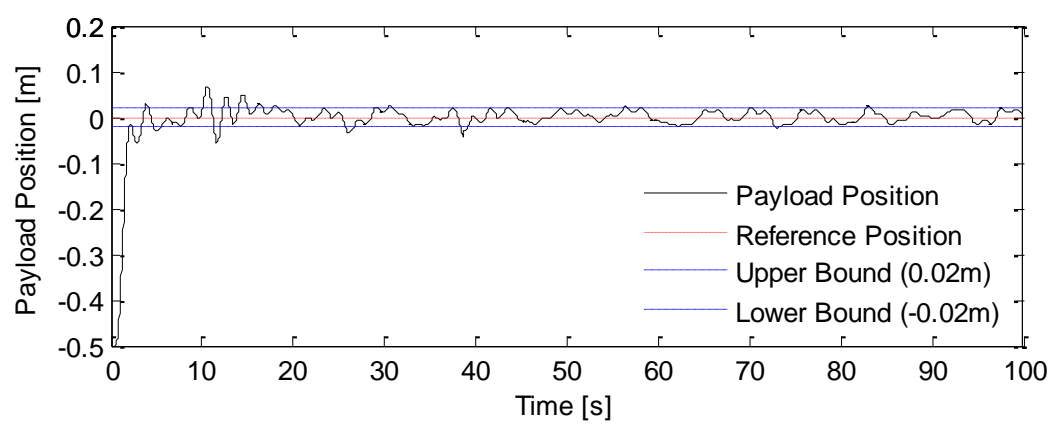

(a) Payload position

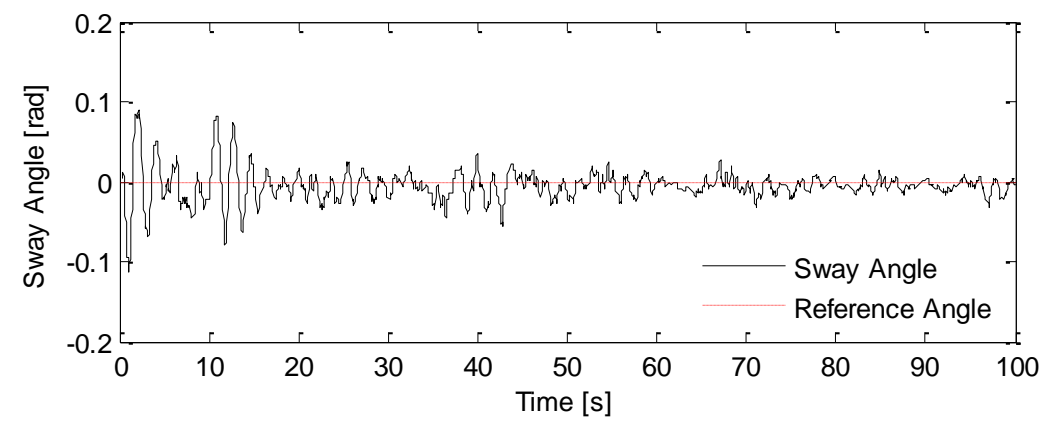

(b) Sway angle

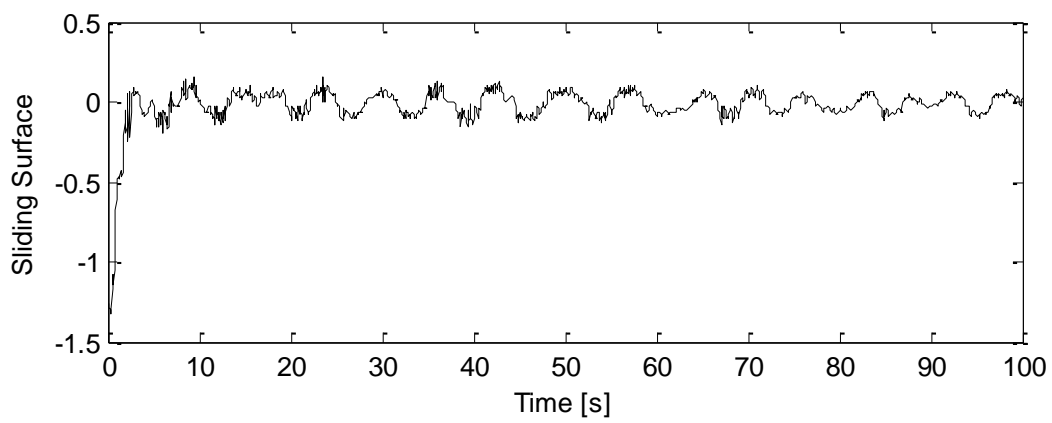

(c) Sliding function

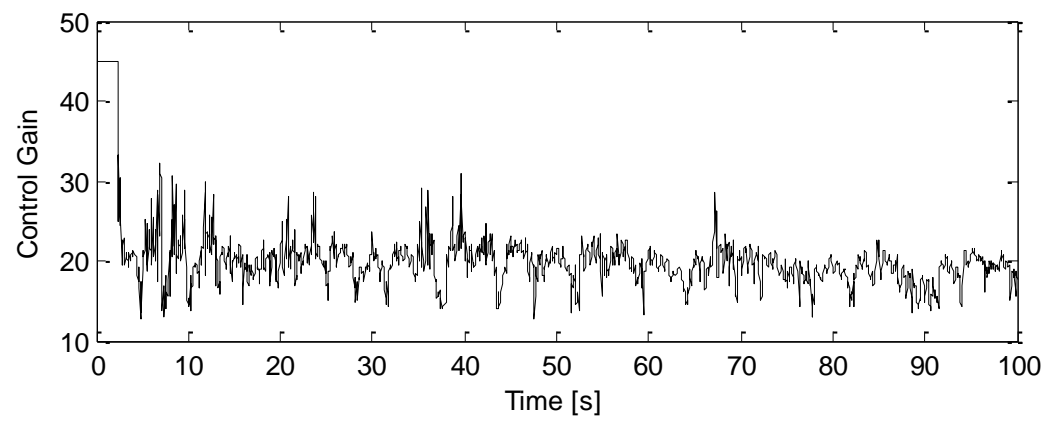

(d) Control gain

Fig. 13. Experimental results with MH roll motion under the proposed control strategy. 


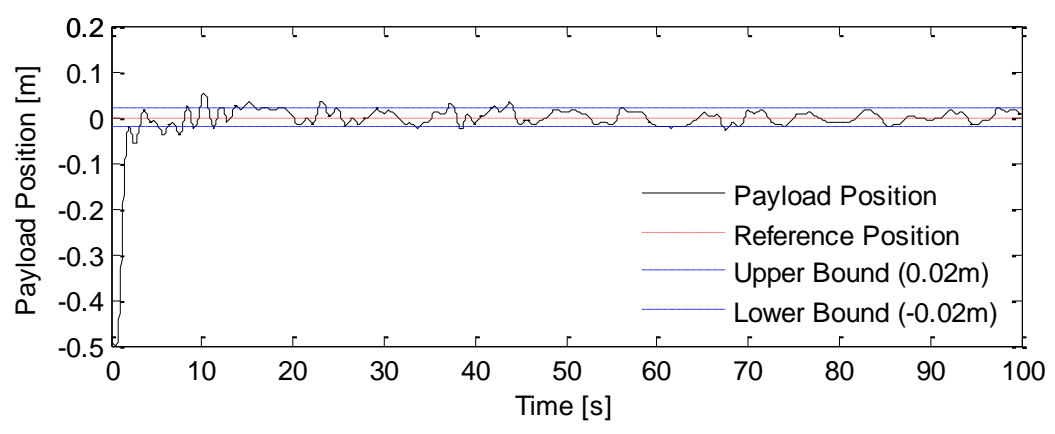

(a) Payload position

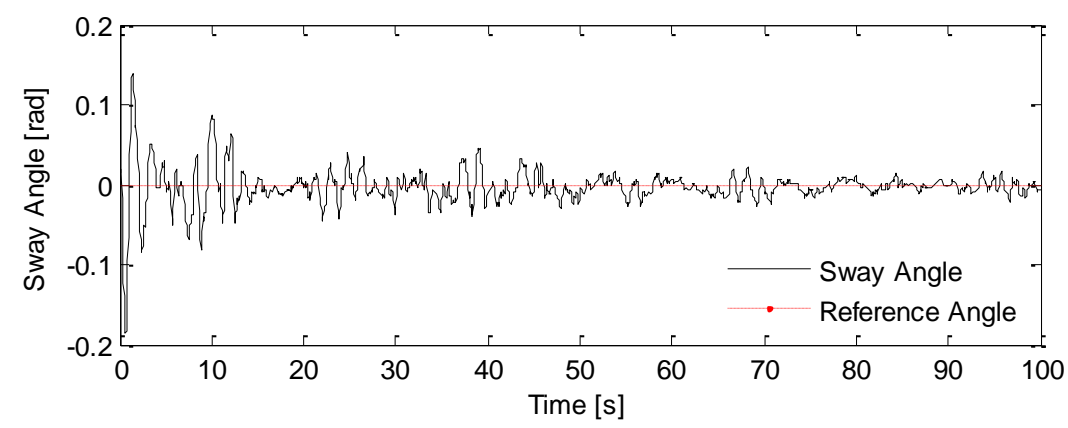

(b) Sway angle

Fig. 14. Robustness illustration - rope length decrease to $0.5 \mathrm{~m}$.

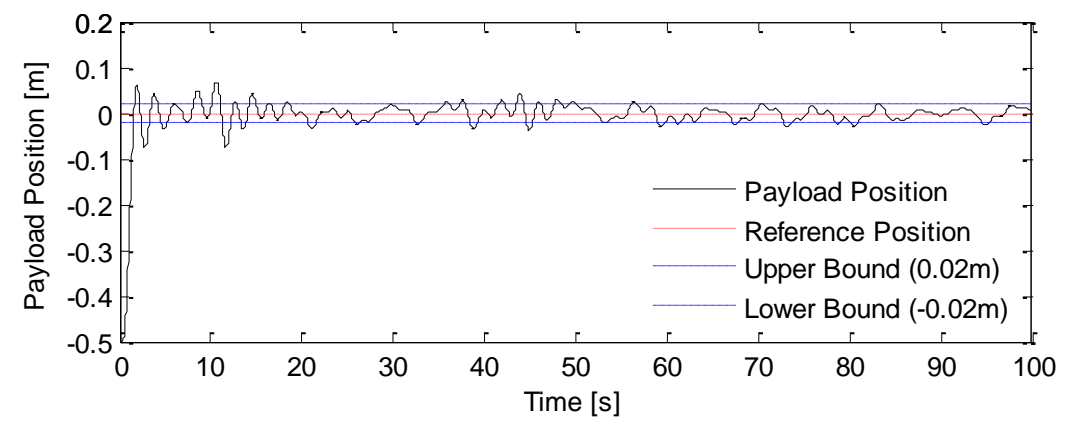

(a) Payload position

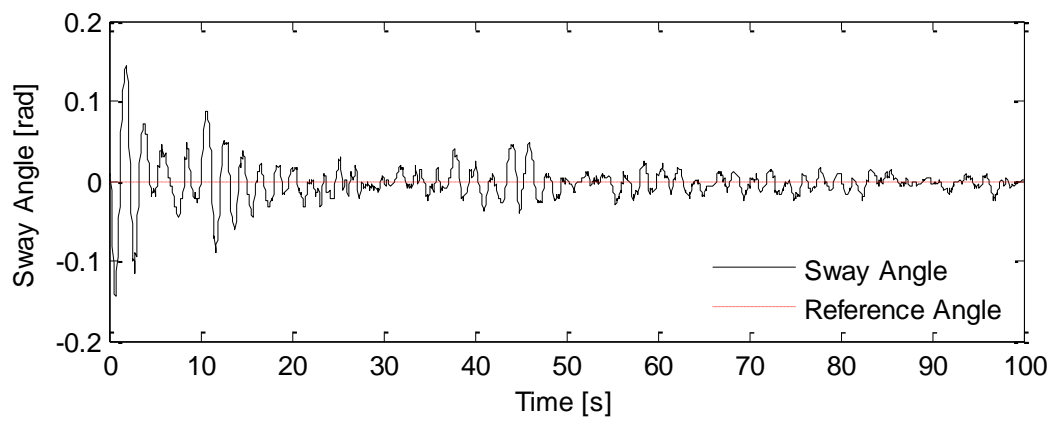

(b) Sway angle

Fig. 15. Robustness illustration - rope length increase to $0.85 \mathrm{~m}$. 


\section{Conclusion}

This paper has presented a new control strategy for offshore stevedoring with the use of a container crane mounted a mobile harbor. The proposed scheme involves fuzzy sliding mode control for trajectory tracking and sway angle suppression, path generation for wave-induced vibration compensation and Kalman filtering for estimation of the mobile harbor's roll angle. In the FSMC law, a high value is applied first to the discontinuous gain to reach the sliding surface. Then, chattering is avoided by fuzzy tuning of the control gain in accordance with the sliding function of the trolley trajectory error and the sway angle as well as its rate of change. The mobile harbor motion is estimated by prediction of the next impact of sea waves to the mobile harbor. This is, in turn, used to generate a desired trajectory for trolley motion in keeping the sway angle in an allowable range. High performance is obtained in tracking the desired trajectory, and hence, keeping the payload position in a small band around its settling value while maintaining an acceptable sway angle, for both the cases of stationary and moving mobile harbor. Robustness of the proposed control strategy is also observed when the system is subject to rope length variations. Simulation and experimental results are provided to illustrate the effectiveness and feasibility of the proposed control strategy for offshore container cranes.

\section{Acknowledgement}

This research was funded by the Vietnam National Foundation for Science and Technology Development (NAFOSTED) under grant number "107.04-2013.28". The first author would like to acknowledge the Endeavour Research Fellowship 2015, supported by the Australian Government.

\section{References}

Ahmad, M.A., 2009. Active sway suppression techniques of a gantry crane system. European journal of scientific research 27 (3), 322-333.

Al-Garni, A.Z., Moustafa, K.A.F., Javeed Nizami, S.S.A.K., 1995. Optimal control of overhead cranes. Control Engineering Practice 3 (9), 1277-1284.

Almutairi, N.B., Zribi, M., 2009. Sliding mode control of a three-dimensional overhead crane. Journal of vibration and control 15 (11), 1679-1730.

Bartolini, G., Pisano, A., Usai, E., 2002a. Output-feedback control of container cranes: a comparative analysis, Proceedings of the 41st IEEE Conference on Decision and Control, pp. 3237-3242. 
Bartolini, G., Pisano, A., Usai, E., 2002b. Second-order sliding-mode control of container cranes. Automatica 38 (10), 1783-1790.

Benhidjeb, A., Gissinger, G.L., 1995. Fuzzy control of an overhead crane performance comparison with classic control. Control Engineering Practice 3 (12), 1687-1696.

Cha, J.-H., Roh, M.-I., Lee, K.-Y., 2010. Dynamic response simulation of a heavy cargo suspended by a floating crane based on multibody system dynamics. Ocean Engineering 37 (14-15), 1273-1291.

Chang, C.-Y., Chiang, K.-H., 2008. Fuzzy projection control law and its application to the overhead crane. Mechatronics 18 (10), 607-615.

Chen, Y.-J., Wang, W.-J., Chang, C.-L., 2009. Guaranteed cost control for an overhead crane with practical constraints: Fuzzy descriptor system approach. Engineering Applications of Artificial Intelligence 22 (4-5), 639-645.

Cheng-Yuan, C., 2007. Adaptive Fuzzy Controller of the Overhead Cranes With Nonlinear Disturbance. IEEE Transactions on Industrial Informatics 3 (2), 164-172.

Cho, S.-K., Lee, H.-H., 2002. A fuzzy-logic antiswing controller for three-dimensional overhead cranes. ISA Transactions 41 (2), 235-243.

Clauss, G., Stempinski, F., Dudek, M., Klein, M., 2009. Water depth influence on wave-structureinteraction. Ocean Engineering 36 (17-18), 1396-1403.

Do, K.D., Pan, J., 2008. Nonlinear control of an active heave compensation system. Ocean Engineering 35 (5-6), 558-571.

García-Morales, R.M., Baquerizo, A., Losada, M.Á., 2015. Port management and multiple-criteria decision making under uncertainty. Ocean Engineering 104, 31-39.

Ha, Q.P., Rye, D.C., Durrant-Whyte, H.F., 1999. Fuzzy moving sliding mode control with application to robotic manipulators. Automatica, 35, 607-616.

Hong, K.-S., Ngo, Q.H., 2012. Dynamics of the container crane on a mobile harbor. Ocean Engineering $53,16-24$.

Hong, K.-S., Park, B.-J., Lee, M.-H., 2000. Two-stage control for container cranes. JSME International Journal Series C 43 (2), 273-282.

Hong, K.T., Huh, C.-D., Hong, K.S., 2003. Command shaping control for limiting the transient sway angle of crane systems. International Journal of Control, Automation, and Systems 1 (1), 43-53.

Huey, J.R., Sorensen, K.L., Singhose, W.E., 2008. Useful applications of closed-loop signal shaping controllers. Control Engineering Practice 16 (7), 836-846. 
Janabi-Sharifi, F., Hayward, V., Chen, C.S.J., 2000. Discrete-time adaptive windowing for velocity estimation. IEEE Transactions on Control Systems Technology 8 (6), 1003-1009.

Kim, Y.-S., Hong, K.-S., Sul, S.-K., 2004. Anti-sway control of container cranes: inclinometer, observer, and state feedback. International Journal of Control, Automation, and Systems 2 (4), 435-449.

Kłosiński, J., 2005. Swing-free stop control of the slewing motion of a mobile crane. Control Engineering Practice 13 (4), 451-460.

Kuchler, S., Mahl, T., Neupert, J., Schneider, K., Sawodny, O., 2011. Active control for an offshore crane using prediction of the vessel's motion. IEEE/ASME Transactions on Mechatronics 16 (2), 297309.

Kyoung, J.H., Hong, S.Y., Kim, J.W., Bai, K.J., 2005. Finite-element computation of wave impact load due to a violent sloshing. Ocean Engineering 32 (17-18), 2020-2039.

Lee, H.-H., 2004a. A new design approach for the anti-swing trajectory control of overhead cranes with high-speed hoisting. International journal of control 77 (10), 931-940.

Lee, H.-H., 2004b. A new motion-planning scheme for overhead cranes with high-speed hoisting. Journal of Dynamic Systems, Measurement, and Control 126 (2), 359-364.

Lee, H.-H., 2005. Motion planning for three-dimensional overhead cranes with high-speed load hoisting. International journal of control 78 (12), 875-886.

Lee, H.-H., Liang, Y., Segura, D., 2006. A sliding-mode antiswing trajectory control for overhead cranes with high-speed load hoisting. Journal of Dynamic Systems, Measurement, and Control 128 (4), 842-845.

Liu, D., Yi, J., Zhao, D., Wang, W., 2005. Adaptive sliding mode fuzzy control for a two-dimensional overhead crane. Mechatronics 15 (5), 505-522.

Messineo, S., Celani, F., Egeland, O., 2008. Crane feedback control in offshore moonpool operations. Control Engineering Practice 16 (3), 356-364.

Messineo, S., Serrani, A., 2009. Offshore crane control based on adaptive external models. Automatica 45 (11), 2546-2556.

Mizumoto, I., Chen, T., Ohdaira, S., Kumon, M., Iwai, Z., 2007. Adaptive output feedback control of general MIMO systems using multirate sampling and its application to a cart-crane system. Automatica 43 (12), 2077-2085.

Ngo, Q.H., Nan, Y., and Hong, K.-S., 2012. Command shaping for vibration reduction of container cranes, International Conference on Control, Automation and Systems 2012. pp. 651-655. 
Ngo, Q.H., Hong, G., Hong, K.-S., 2011. Sway suppression of an offshore container crane, IEEE/SICE International Symposium on System Integration (SII). IEEE, pp. 1388-1393.

Ngo, Q.H., Hong, K.-S., 2012a. Adaptive sliding mode control of container cranes. IET Control Theory \& Applications 6 (5), 662-668.

Ngo, Q.H., Hong, K.-S., 2012b. Sliding-mode antisway control of an offshore container crane. IEEE/ASME Transactions on Mechatronics 17 (2), 201-209.

Omar, F., Karray, F., Basir, O., Yu, L., 2004. Autonomous overhead crane system using a fuzzy logic controller. Journal of vibration and control 10 (9), 1255-1270.

Orbisaglia, M., Orlando, G., Longhi, S., 2008. A comparative analysis of sliding mode controllers for overhead cranes, 16th Mediterranean Conference on Control and Automation. IEEE, pp. 670-675.

Pang, K.-W., Liu, J., 2014. An integrated model for ship routing with transshipment and berth allocation. IIE Transactions 46 (12), 1357-1370.

Park, H., Chwa, D., Hong, K., 2007. A feedback linearization control of container cranes: Varying rope length. International Journal of Control Automation and Systems 5 (4), 379.

Raja Ismail, R.M.T., Ha, Q., 2012. Second-order Sliding Mode Control for Offshore Container Cranes, Proceedings of Australasian Conference on Robotics and Automation, 3-5 Dec 2012, New Zealand.

Raja Ismail, R.M.T., That, N.D., Ha, Q.P., 2015. Modelling and robust trajectory following for offshore container crane systems. Automation in Construction 59, 179-187.

Ranga Rao, A.V., Sundaravadivelu, R., 1999. A knowledge based expert system for design of berthing structures. Ocean Engineering 26 (7), 653-673.

Robertson, M.J., Singhose, W.E., 2009. Robust discrete-time deflection-limiting commands for flexible systems. Control Theory \& Applications, IET 3 (4), 473-480.

Sawodny, O., Aschemann, H., Lahres, S., 2002. An automated gantry crane as a large workspace robot. Control Engineering Practice 10 (12), 1323-1338.

Singhose, W., Porter, L., Kenison, M., Kriikku, E., 2000. Effects of hoisting on the input shaping control of gantry cranes. Control Engineering Practice 8 (10), 1159-1165.

Skaare, B., Egeland, O., 2006. Parallel Force/Position Crane Control in Marine Operations. Oceanic Engineering, IEEE Journal of 31 (3), 599-613.

Sorensen, K.L., Singhose, W., Dickerson, S., 2007. A controller enabling precise positioning and sway reduction in bridge and gantry cranes. Control Engineering Practice 15 (7), 825-837. 
Sorensen, K.L., Singhose, W.E., 2008. Command-induced vibration analysis using input shaping principles. Automatica 44 (9), 2392-2397.

Steenken, D., Voß, S., Stahlbock, R., 2004. Container terminal operation and operations research - a classification and literature review. OR Spectrum 26 (1), 3-49.

Sung, Y.-G., Singhose, W.E., 2009a. Limited-state commands for systems with two flexible modes. Mechatronics 19 (5), 780-787.

Sung, Y.G., Singhose, W.E., 2009b. Robustness analysis of input shaping commands for two-mode flexible systems. IET control theory \& applications 3 (6), 722-730.

Tuan, L., Moon, S.-C., Lee, W., Lee, S.-G., 2013. Adaptive sliding mode control of overhead cranes with varying cable length. Journal of Mechanical Science and Technology 27 (3), 885-893.

Xi, Z., Hesketh, T., 2010. Discrete time integral sliding mode control for overhead crane with uncertainties. IET control theory \& applications 4 (10), 2071-2081.

Yang, J.H., Yang, K.S., 2007. Adaptive coupling control for overhead crane systems. Mechatronics 17 (2), 143-152.

Yin, X.F., Khoo, L.P., Chen, C.-H., 2011. A distributed agent system for port planning and scheduling. Advanced Engineering Informatics 25 (3), 403-412.

Zhu, G., Borthwick, A.G.L., Eatock Taylor, R., 2001. A finite element model of interaction between viscous free surface waves and submerged cylinders. Ocean Engineering 28 (8), 989-1008. 